\title{
ASPECTOS DO ENSINO E APRENDIZAGEM DA ORALIDADE NA ESCOLA
}

ASPECTS OF TEACHING AND LEARNING ORAL LANGUAGE IN SCHOOL

José Batista de Barros | Lattes | jose.bbarros@ufpe.br Universidade Federal de Pernambuco | Universidade Católica de Pernambuco Paula Roberta Paschoal Boulitreau | Lattes | roberta.boulitreau@capufpe.com Universidade Federal de Pernambuco | Universidade Católica de Pernambuco Adriana Letícia Torres da Rosa | Lattes | adriana.trosa@ufpe.br Universidade Federal de Pernambuco

Resumo: Objetivamos refletir sobre os aspectos relativos ao ensino-aprendizagem da oralidade na sala de aula, dirigindo o olhar para os gêneros textuais como organizadores das práticas sociais e discursivas. Realizamos uma pesquisa qualitativa, na qual aplicamos a entrevista narrativa com dois professores de escolas públicas de Pernambuco que ensinam língua portuguesa em diferentes realidades (uma municipal e uma federal). Os professores demonstram reconhecer que a participação significativa do indivíduo nas práticas sociais, a partir do uso da linguagem oral, reflete nos processos de inclusão; apontam como importante o trabalho com a diversidade de gêneros orais, e variedades linguísticas; e, sinalizam questões históricas quanto ao trabalho do livro didático com a oralidade, indicando as necessidades de se investir na pedagogia de ensino da "fala". Concluímos que o estudante tem a possibilidade de ampliar seus conhecimentos quando a escola se apresenta como espaço de sistematização do saber construído sócio historicamente, numa perspectiva inclusiva.

Palavras-chave: Oralidade. Inclusão social. Gêneros textuais. Ensino de língua portuguesa. 


\begin{abstract}
We aim to reflect on the aspects related to the teaching-learning of oral language in the classroom, taking into account textual genres as organizers of social and discursive practices. We conducted a qualitative research, in which we administered the narrative interview with two public school teachers in Pernambuco who teach Portuguese in different realities (one municipal and one federal school). Teachers recognize that the significant individual participation in social practices with the use of oral language reflects in the processes of inclusion; point out the importance of working with the diversity of oral genres and linguistic varieties; and thehistorical questions about the use of the textbook and oral language, indicating the need to invest in the pedagogy of "speech" teaching. We conclude that the student has the possibility to increase his knowledge when the school presents itself as a space for systematization of historically constructed knowledge, in an inclusive perspective.
\end{abstract}

Keywords: Oral language. Social inclusion. Textual genres. Portuguese language teaching.

\title{
1 CONSIDERAÇÕES INICIAIS
}

A linguagem, segundo Bakhtin/Volochínov (2002), é uma forma de interação social que permeia as nossas ações desde os nossos primeiros passos. Ouvimos, lemos e produzimos textos diariamente com intuito de agir em comunidade, se posicionando socialmente. Em especial, a produção de textos permite-nos participar de diversas situações e exigências comunicativas importantes, sejam elas menos ou mais formais.

Cabe, pois, à escola promover situações de ensino-aprendizagem de produção de textos escritos e orais, a fim de garantir aos alunos o direito de compreensão e interação em situações de uso da linguagem no seu cotidiano, público e privado.

No que se refere à oralidade, muito se questiona que a "fala" cabe à escola ensinar. A nosso ver, na escola, o aluno tem a possibilidade de ampliar seus conhecimentos, passando por interações informais a formais. Os gêneros da oralidade têm um papel de destaque: o estudo das ações discursivas que passam pelo uso dos mesmos, e das formas de materializá-los que oferecem ao estudante ferramentas para que possa participar mais efetivamente do cotidiano social no qual se insere. 
Nesse contexto, a análise dos compassos e descompassos pedagógicos no tratamento dos gêneros orais nos dará subsídios para, enquanto profissionais da educação, reposicionarmos o seu uso em sala de aula, e, também, enquanto professores pesquisadores, apresentarmos uma contribuição para o campo didático no que tange à necessidade de constante aprimoramento das publicações, para se ajustarem às demandas teóricas e metodológicas que se apresentam em discussão nos estudos contemporâneos.

Buscamos, com esse trabalho, possíveis respostas para a questão de ordem investigativa que se coloca: Que pressupostos teórico-metodológicos estão subjacentes às propostas de ensino-aprendizagem do texto oral na escola pública?

Com base nesse questionamento, elegemos como objetivo geral deste trabalho, analisar as abordagens pedagógicas do trabalho com a oralidade, especialmente, com os gêneros textuais no ensino de língua materna. Desse modo, identificar as suas contribuições para a formação do aluno enquanto sujeito agente da comunicação sociointerativa humana, e, consequentemente, para sua inclusão no mundo social letrado.

Quanto aos aspectos metodológicos, destacamos que a análise em tela teve base qualitativa. $\mathrm{O}$ corpus da investigação foi composto por duas entrevistas realizadas com professores do Ensino Fundamental. Assim, ressaltamos princípios norteadores para organização de situações didáticas que envolvam a produção de textos orais, considerando as relações complementares entre a fala e a escrita observadas em duas escolas públicas, sendo uma municipal, em Olinda, e uma federal, em Recife.

\section{METODOLOGIA}

Buscamos traçar um percurso metodológico que fosse coerente com o objetivo delineado. Para tanto, partimos do pressuposto de que a ciência é todo conhecimento sistematizado a partir de procedimentos metodológicos bem definidos.

Consideramos, enquanto base metodológica, a Etnometodologia. Esse paradigma parte do pressuposto de que pesquisar pressupõe compreensão da realidade/meio social in loco. Por isso, se fez necessário que, enquanto pesquisadores, nos inseríssemos no campo em estudo.

A pesquisa em voga teve, portanto, natureza aplicada e qualitativa, uma vez identificada a impossibilidade de vislumbrar o objeto a partir de dados quantificáveis mensurados em formatos numérico, mas sim, levando em conta determinado contexto (MINAYO, 2006). 
De acordo com Souza Júnior, Melo e Santiago (2010), as pesquisas qualitativas são estruturadas em três etapas: a fase exploratória, a coleta de dados e a análise de dados.

Durante a fase exploratória, utilizamos Bakhtin/ Volochínov (2002), Marcuschi (2008) e os Parâmetros Curriculares Nacionais (1998) como principais referências para a fundamentação no campo da linguística.

A coleta de dados consistiu na aplicação de uma entrevista narrativa, realizada com dois professores, sendo um da Rede Municipal de ensino de Olinda/PE e outro de uma escola pública federal. Ambos com estudos especializados no campo da linguística e atuando na educação básica, mas em níveis de ensino diferentes, para que pudéssemos observar mais de um ciclo de formação.

As entrevistas foram realizadas no segundo semestre de 2018 e a escolha do corpus da pesquisa deu em função do conhecimento sobre práticas pedagógicas exitosas dos docentes.

Durante a entrevista buscamos saber: Que pressupostos teórico-metodológicos estão subjacentes às propostas de ensino-aprendizagem do texto oral na escola pública? Com base nesse questionamento, analisamos abordagens pedagógicas do trabalho com a oralidade, no ensino de língua materna. E, desse modo, identificamos as suas contribuições para a formação do aluno enquanto sujeito agente da comunicação sociointerativa humana, e, consequentemente, para sua inclusão no mundo social letrado. Diante do questionamento, cada entrevistado apresentou suas perspectivas. A primeira entrevista durou 21 minutos e 39 segundos (P1) e a segunda durou 16 minutos e 52 segundos (P2).

Para análise e sistematização dos dados, utilizamos a análise de conteúdo de Bardin (2009).

Na sequência do artigo, apresentamos as discussões iniciais realizadas durante a etapa da fase exploratória (Linguagem e língua; Oralidade e letramento; Da escrita para fala) e, em seguida, trazemos a análise dos apontamentos dos professores em questão.

\section{LINGUAGEM E LÍNGUA: TECENDO REDES INTERATIVAS}

Como destacamos, a linguagem é uma forma de interação social e a língua, linguagem verbal, assim, é observada como um fenômeno interativo e dinâmico que envolve atividades de diálogo e de negociação entre indivíduos, socialmente posicionados, em diferentes contextos situacionais de uso. 
A referida concepção ancora-se nos estudos de Bakhtin/Volochínov (2002) o qual, nas suas reflexões sobre a filosofia da linguagem, defende que a "palavra" se constitui no diálogo, fruto da interação entre sujeitos organizados, situada num contexto social, e, nesse caso, a língua insere-se num processo ininterrupto de evolução pautado na interação verbal social dos locutores.

Na mesma linha de pensar, Marcuschi (2001) observa que é importante distinguir os termos Linguagem e Língua, pois aparentemente sinônimos, designam fenômeno distintos e complementares.

a) A expressão linguagem designa uma faculdade humana, isto é, a faculdade de usar signos com objetivos cognitivos. A linguagem é um dispositivo que caracteriza a espécie humana como homo sapiens, ou seja, como um sujeito reflexivo, pois a linguagem é um fenômeno humano, hoje tido como inato e geneticamente transmitido pela espécie.

b) A expressão língua refere uma das tantas formas de manifestação concreta dos sistemas de comunicação humanos desenvolvidos socialmente por comunidades linguísticas e se manifesta como atividades sócio-cognitiva para a comunicação interpessoal (MARCUSCHI, 2001, p. 20).

Nessa perspectiva, uma língua, linguagem verbal, constitui-se no sistema de interação linguística entre indivíduos, que enquanto interlocutores, constroem sentidos e significados ao interagirem com o grupo social. Tais interações, orais ou escritas, constituem representações que variam de acordo com a relação que cada indivíduo tem com a língua, com o que o sujeito fala, ouve, lê e escreve. Apropriar-se da língua, implica inserir-se na dinâmica do mundo natural e social, identificando, compreendendo, significando e articulando os saberes e vínculos constituídos.

Na nossa fala, e compreenda-se aqui fala como manifestação da linguagem verbal, oral ou escrita, usamos a língua para dizer a e agir sobre uma realidade que construímos discursivamente. Defendemos, junto a vários autores, como Bakhtin (1997), por exemplo, que a comunicação humana se estabelece mediante o uso de algum gênero do discurso: os gêneros organizam a nossa fala e escrita, sem os quais ficaria quase impossível interagirmos.

Para Bakhtin (1997):

Todos os diversos campos da atividade humana estão ligados ao uso da linguagem. Compreende-se perfeitamente que o caráter e as formas desse uso sejam tão multiformes quanto os campos da atividade humana, o que, é claro, não contradiz a unidade nacional de uma língua. $\mathrm{O}$ emprego da língua efetua-se em forma de enunciados (orais e escritos) concretos e únicos, proferidos pelos integrantes desse ou daquele campo da atividade humana. Esses enunciados refletem as condições específicas e as finalidades de cada referido campo não só por seu conteúdo (temático) e pelo estilo da linguagem, ou seja, pela seleção dos recursos lexicais, fraseológicos e gramaticais da língua mas, acima de tudo, por sua composição composicional (BAKHTIN, 1997, p. 261). 
De acordo com as proposições bakhtinianas, os gêneros são entidades históricas e sociais elaborados nas diversas esferas da atividade humana, como a jurídica, a jornalística, a empresarial, familiar, entre tantas outras, compreendendo relações entre sujeitos e seus propósitos de interação. Nessa linha de pensar, destacamos ainda que são formas de ação social imprescindíveis para qualquer interação comunicativa.

É importante dizer que compreendemos os gêneros como "os textos materializados que encontramos em nossa vida diária e que apresentam características sócio-comunicativas definidas por conteúdos, propriedades funcionais, estilo e composição característica” (MARCUSCHI, 2002, p. 22).

Alguns exemplos de gêneros textuais seriam: telefonema, sermão, carta comercial, romance, bilhete, reportagem, piada, conferência, conversação espontânea, bate papo por computador e assim por diante.

\section{ORALIDADE E LETRAMENTO: NA ESCOLA, O QUE SERIA MAIS IMPORTANTE ENSINAR?}

As práticas sociais de oralidade e letramento são povoadas pelo uso dos diversos gêneros textuais. Cabe ressaltar a distinção entre as duas práticas citadas:

Oralidade seria uma prática social interativa para fins comunicativos que se apresenta sob várias formas ou gêneros textuais fundados na realidade sonora que vai desde uma realização mais informal a mais formal nos mais variados contextos de uso $[. .$.

Letramento, por sua vez, envolve as mais diversas práticas da escrita (nas suas variadas formas) na sociedade e pode ir desde uma apropriação mínima da escrita, [...], até uma apropriação aprofundada $[. .$. (MARCUSCHI, 2004, p. 25).

Marcuschi (2004, p.16) traz à baila a discussão sobre o entendimento da língua e do texto como "um conjunto de práticas sociais", de maneira que a oralidade e o letramento sejam vistos como atividades não dicotômicas, mas, sobretudo interativas e complementares situadas sócio-historicamente no âmbito dos usos da língua. Com esse olhar, o autor aponta os usos da língua como determinantes das escolhas formais, e não o contrário como preconizado nos trabalhos da Linguística, anteriores à década de 1980.

Tomando o letramento como prática social formalmente associada ao uso da escrita, ao passo que a oralidade ao uso da fala, o pesquisador observa a necessidade e a importância dessas práticas nas sociedades como via de acesso à cultura. Sobre esse as- 
pecto, o autor, faz uma observação de caráter teórico: oralidade e escrita têm correlação com a noção de "práticas sociais" de uso da língua, ao passo que fala e escrita, podem ser tomadas, por alguns estudiosos, em uma distinção entre "modalidades de usos da língua" (forma de produção textual-discursiva para fins comunicativos - uso da língua na sua forma de sons sistematicamente articulados e significativos; ou na sua constituição gráfica). Contudo, essas distinções nem sempre são expostas de forma explícita nos estudos da atualidade, sendo os termos, por vezes, tomados como sinonímicos - letramento-escrita, oralidade-fala.

Marcuschi (2004) evidencia, todavia, que nas comunidades letradas, a escrita, embora tenha surgido posteriormente à fala, tornou-se um bem social indispensável, sendo supervalorizada em relação àquela, simbolizando educação, desenvolvimento e poder. Desse modo, pode-se dizer que há uma forte cultura ideológica de associação à escrita de um forte prestígio social - mesmo que ainda hoje existam sociedades não letradas, ou mesmo que nas sociedades letradas, a oralidade seja uma atividade comunicativa inegavelmente insubstituível.

Contudo, reforçamos, é notória a defesa de que a oralidade e o letramento não são sistemas dicotômicos, tão pouco, a primeira abarca o caos comunicativo: ambos permitem, com suas peculiaridades, a construção de textos coesos e coerentes, a elaboração formal e informal, a construção de raciocínio, a variação linguística, entre outros aspectos. Para alicerçar esse pensamento, o autor faz um passeio explicativo da presença da oralidade e do letramento na sociedade. Mostra que a escrita e a fala são usadas em variados contextos da vida cotidiana (casa, trabalho, escola, supermercado, etc.), com finalidades múltiplas, organizadas em diversos gêneros textuais, fundados na realidade gráfica, escritos, ou na sonora, orais.

Com essa linha de pensar, Marcuschi (2004) reavalia o papel da oralidade e da escrita na atualidade, apontando a indispensabilidade de ambas, e alertando sobre o fato de não se confundir os papéis e os contextos de seus usos, bem como de não se discriminar os seus usuários.

É nesse sentido que caminham os Parâmetros Curriculares Nacionais (PCNs), quando orientam que a escola é um espaço privilegiado para o estudo da diversidade de gêneros que nos circundam. Os gêneros de realização oral e os de realização escrita devem ser alvos de ensino nas atividades de leitura, escuta e produção de textos como forma de ampliar o universo discursivo dos alunos tanto no plano da oralidade quanto no do letramento. 
A atividade de fala, modalidade oral da língua, mostra-se, desde muito cedo, como fundamental antes mesmo de se dar a aquisição da escrita. Já nascemos nos comunicando: através do choro, por exemplo, o bebê interage com o adulto, passando informações sobre o que sente; a fala, posteriormente, antes mesmo de a criança frequentar os bancos escolares, já se trata do mais importante meio de interação pela linguagem do ser humano.

Contudo, quando se trata da escola, esta importância se inverte, o estudo da fala, muitas vezes, está relegado a segundo plano, centrando-se quase que todos os esforços no da escrita. O equívoco se dá quando se subtende uma ideia de que já se domina a fala, e, portanto, a escrita deve ser mais enfatizada. Mas na realidade, é cada vez mais clara a preocupação que se deve ter com a oralidade e que essa deve ser partilhada pelos responsáveis pelo ensino da língua materna.

Nesse contexto pedagógico, verifica-se ainda uma prática escolar de valorização do trabalho com a escrita em detrimento do trabalho com a oralidade, fruto de uma visão tradicional da língua gerada pela própria circunstância de avaliação social e histórica do registro escrito como de poder.

Todavia, essa relação dicotômica fala-escrita precisa ser revista, pois não se coaduna com a concepção de interatividade linguística. Nessa seara, partilhamos das ideias de Marcuschi (2004) de que:

oralidade e escrita são práticas e usos da língua com características próprias, mas não suficientemente opostas para caracterizar dois sistemas linguísticos nem uma dicotomia. Ambas permitem a construção de textos coesos e coerentes, ambas permitem a elaboração de raciocínios abstratos e exposições formais e informais, variações estilísticas, sociais, dialetais e assim por diante (MARCUSCHI, 2004, p. 17).

A oralidade e a escrita estão presentes na sociedade e são amplamente usadas em contextos da vida cotidiana mesmo por aqueles que não possuem um grau de escolaridade amplo: na família, no trabalho, na vida institucional em geral, e também na escola, entramos em contato com distintos usos e objetivos de uso da escrita e da oralidade. E caminhar com maior firmeza pelas múltiplas esferas das práticas discursivas sociais nos exige um aprofundamento do estudo de ambas as modalidades.

Uma modalidade está intimamente ligada à outra. Dizer qual a mais importante, definitivamente não é "importante". O que se quer é o reconhecimento do valor tanto da oralidade como da escrita, na vida, principalmente, acadêmica do indivíduo. Assim, o espaço da oralidade deve ser garantido na sala de aula, a escuta e a produção dos gêneros orais possibilitam a inserção do aluno em contextos e situações, particulares e públicas, relevantes de uso da linguagem. 


\section{DA ESCRITA PARA FALA: GÊNEROS DA ORALIDADE NA SALA DE AULA}

Tomando-se a concepção de língua como um conjunto de práticas sociais prontas a atender às mais diversas necessidades humanas, torna-se inviável tecer relações entre fala e escrita, e pesquisar oralidade e letramento, desconsiderando seus usos no dia a dia. Lembra-nos Marcuschi (2004) que ambas, fala e escrita, são imprescindíveis para a sociedade não se devendo, portanto confundir os papéis, muito menos instigar a discriminação dos seus usuários.

Essa forma de pensar ajusta-se por hora às orientações dos PCNs (1997, p. 32) quando norteiam que "falar bem é falar adequadamente, é produzir o efeito pretendido" o que deságua no ideal de ensino da linguagem oral tendo em vista a diversidade de situações comunicativas, especialmente as mais formais: entrevistas, debates, seminários, dramatizações, entre outras.

Os referidos Parâmetros ao tratar dos objetivos de língua portuguesa para os anos iniciais da Educação Básica apontam que o ensino-aprendizagem deve levar o aluno a utilizar a linguagem oral com eficácia, adequando-a as mais variadas situações de comunicação, sejam públicas ou privadas, expressando opiniões, defendendo pontos de vista, relatando fatos e expondo os temas estudados; deve também habilitar o aluno a participar das situações comunicativas, acolhendo e considerando as opiniões alheias, respeitando os diferentes modos de falar.

Assim, uma abordagem pedagógica significativa para desenvolver o trabalho de ensino de língua materna que não relega a importância da "fala" seria o estudo-aprendizagem dos gêneros textuais orais. Com essa abordagem não se pretende ensinar o aluno a falar, mas a compreender e fazer usos, situados (social e historicamente) e adequados da linguagem oral. Concordamos com o entendimento de que

\footnotetext{
o estudo dos gêneros pode ter consequência positiva nas aulas de português, pois leva em conta seus usos e funções numa situação comunicativa. Com isso, as aulas podem deixar de ter um caráter técnico dogmático e/ou fossilizado, pois a língua a ser estudada poderá construir seu conhecimento na interação com o objeto de estudo, mediado por parceiros mais experientes (BEZERRA, 2002, p. 41).
}

Uma relevante oportunidade de se trazer o estudo dos gêneros para escola seria traçar considerações sobre aproximações e distanciamentos dos gêneros orais e escritos, considerando o meio de produção (sonoro e/ou gráfico) e a sua concepção discursiva (oral e/ ou escrita). Isso revelará uma visão não-dicotômica de língua, na medida em que evidenciará que as manifestações da fala e da escrita se dão num contínuo dos gêneros textuais. Marcuschi (2004) formula um gráfico representativo dessas relações: 


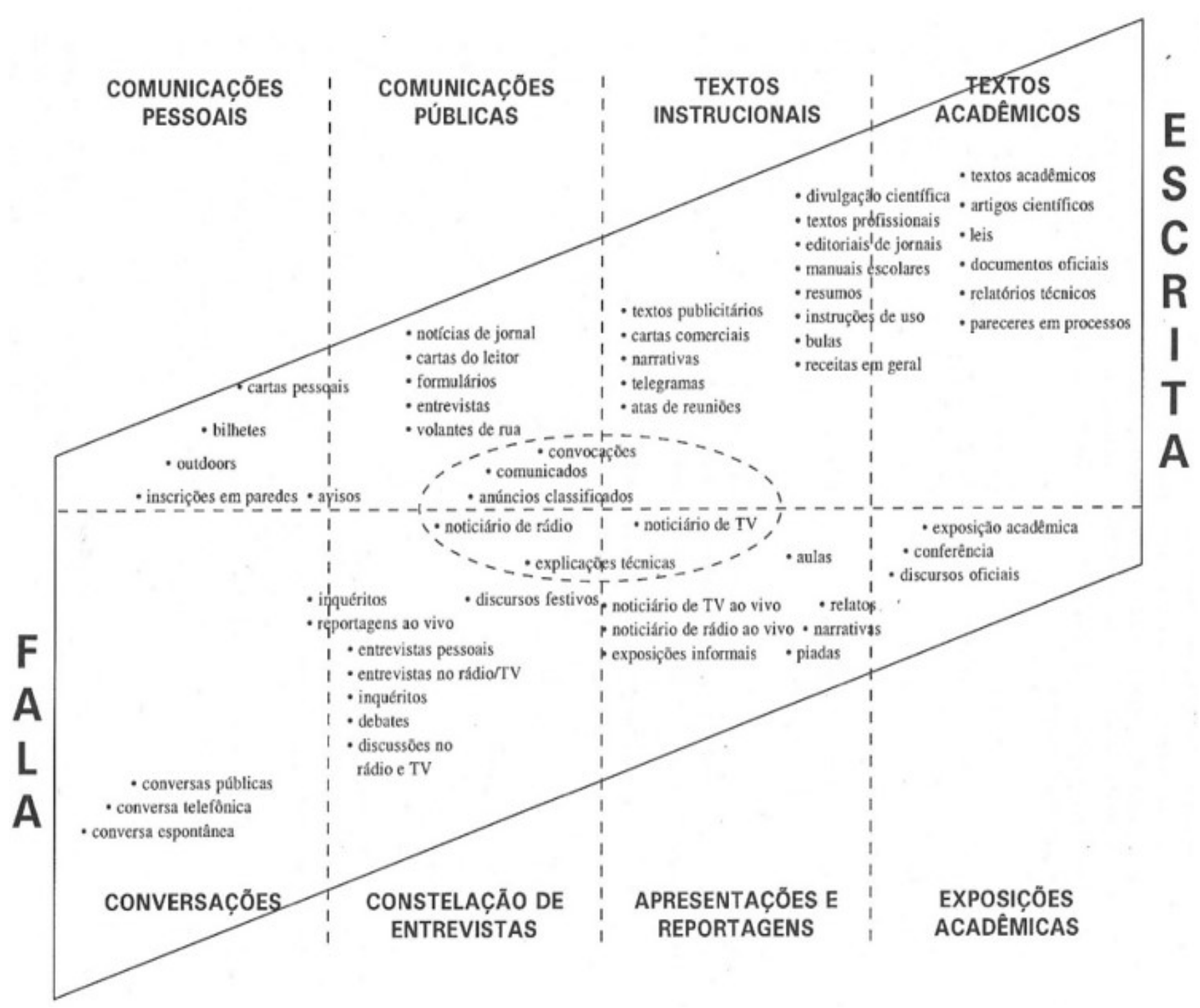

Imagem 1 - Representação do contínuo dos gêneros textuais na fala e na escrita segundo Marcuschi (2004, p. 41).

Com isso observamos que conversas espontâneas aproximam-se de cartas pessoais no que se refere ao nível de formalidade de linguagem exigido, distanciando-se das estratégias de formulação quanto à composição e ao estilo de outros gêneros como conferência e relatórios. Considerando apenas o espaço da oralidade, por exemplo, verificamos que há uma progressão no que tange às exigências do grau de formalidade, da seleção lexical, das formas de ação dos interlocutores ao participarem de interações de escuta ou produção mediadas por distintos gêneros como conversas telefônicas, debates, noticiário de rádio ou $T V$, aulas ou discursos oficiais. 
É nessa linha de pensar que nos norteiam os PCNs (1997), quanto às abordagens da oralidade em sala de aula:

partam das capacidades comunicativas dos alunos antes do ensino;

ofereçam um corpus de textos organizados nos gêneros previstos como referência modelizadora;

proponham atividades no interior de um projeto que deixe claro para o aluno os parâmetros da situação de comunicação;

isolem os diferentes componentes do gênero a ser trabalhado e organizam o ensino dos conteúdos, estabelecendo progressão coerente;

reintroduzam os componentes trabalhados isoladamente no interior de novas atividades de produção de textos orais, o que possibilita avaliar a apropriação dos conhecimentos pelos alunos e as estratégias de ensino (BRASIL, 1997, p. 71).

Nesse contexto, a prática de compreensão e de produção de textos orais além de pautar-se no estudo das relações fala-escrita, também ancora-se na organização de situações didáticas que favoreçam o desenvolvimento de procedimentos de preparação prévia e monitoramento da fala.

\section{ORALIDADE EM SALA DE AULA: CONCEPÇÕES DOS DOCENTES}

Com o propósito de identificar os aspectos do ensino-aprendizagem da oralidade na escola, realizamos entrevistas narrativas com dois docentes de escolas públicas: P1 - professor licenciado em Letras, doutor em Linguística, vinculado a uma escola pública federal de Pernambuco; P2 - professor licenciado em Pedagogia, mestrando em Linguística, vinculado a uma escola pública municipal de Olinda - PE. As respostas dos professores são um indicativo de como a oralidade vem sendo tratada em algumas escolas no estado.

Ao questionarmos os professores sobre que fala cabe à escola ensinar, o P1 apontou que o foco deve ser no ensino da "fala" pública. Para o docente, em correlação com a "fala" usada em ambientes mais informais, como o cotidiano familiar ou nos discursos entre amigos, a escola deve sistematizar situações de uso da fala gradativamente mais formal e elaborada, inclusive com inter-relações nítidas com a escrita. Já o P2 entende que o trabalho com as duas modalidades (oral e escrita) deve estar no cotidiano das aulas ministradas nas escolas, nas diferentes disciplinas, e que os professores deixem claro aos seus alunos a importância de ambas na formação acadêmica e cidadã para atuarem 
nas diferentes situações a que estarão expostos no cotidiano. No discurso de ambos os profissionais, percebe-se uma preocupação tanto com o ensino-aprendizagem da escrita quanto com o da oralidade. No primeiro caso, enfatiza-se a relação público-privado no contexto de estudo das práticas da oralidade; no segundo, há uma percepção do caráter interdisciplinar, visão bem típica do pedagogo, e também uma compreensão da função social do ensino da "fala" para inclusão do cidadão em comunidade.

Sobre a importância do ensino da oralidade para a formação do aluno, o P1 defende que essa reside no fato de que o aluno como cidadão, precisa ter competências para participar das diversas instâncias sociais adequadamente, tendo condições de compreender e de se fazer compreendido em diversas variedades linguísticas, situações com graus de formalidades distintos e usos de gêneros textuais diversos. Enquanto que para o P2, o trabalho com os gêneros orais, quando bem orientado, produz efeitos que são visíveis na argumentação das falas e nas articulações das ideias para exposição, colabora em muito para os posicionamentos sociais nas diversas situações comunicativas - formais ou informais - vividas no cotidiano, desenvolve nos indivíduos um posicionamento crítico de análise da realidade. Os docentes comungam com a ideia de que o estudo da oralidade dará subsídios teóricos e práticos para os alunos exercerem sua cidadania. A análise e o uso dos gêneros textuais orais, considerando suas possibilidades comunicativas e textuais, sugerem o desenvolvimento de habilidades sociodiscursivas dos indivíduos.

No tocante à distinção entre oralidade e letramento, P1 observa que, a grosso modo, a oralidade está associada às práticas de uso da linguagem oral, nos seus diversos gêneros textuais; ao passo que o letramento aplica-se às práticas da escrita. P2, por sua vez, compreende letramento como um processo de apropriação de conhecimentos com a escrita que se inicia já na primeira infância e se estende até a vida adulta dos indivíduos no exercício de suas práticas sociais e oralidade como uma capacidade inata de comunicação para o exercício das práticas sociais a que estão expostos os indivíduos. O primeiro professor aponta a oralidade e o letramento como práticas sociais de uso da linguagem, conforme orientam as proposições de Marcuschi (2004); já o segundo, parece ter melhor compreensão do fenômeno do letramento, e quanto ao da oralidade concebe-o, equivocadamente, como uma "capacidade inata" quando, no entanto, trata-se, assim como o letramento, de uma inserção (e não meramente "exposição") em práticas sociais.

Quando questionados sobre o que deve ser enfatizado no ensino-aprendizagem da produção do texto oral na escola, $\mathbf{P 1}$ enfatizou o uso das variedades linguísticas e dos gêneros textuais (com suas particularidades), pois podem garantir a efetiva participação 
social nas práticas interativas. No mesmo caminho, $\mathbf{P 2}$ exaltou a importância do conhecimento da oralidade para a vida social e suas práticas, assim como a função social dos gêneros e seus domínios, as variedades disponíveis e suas características, e ainda sua articulação com a escrita. Para o professor em tela, ambas as modalidades são imprescindíveis para o desenvolvimento do senso crítico, assim como para a formação cidadã. As respostas dos docentes referendam o estudo dos gêneros textuais e das variedades linguísticas como essenciais para o ensino-aprendizagem da oralidade na escola. Desse modo, percebemos nos discursos dos professores a orientação teórica da perspectiva enunciativa de estudo da língua.

Ao sugerirmos que citassem os gêneros orais privilegiados para se trabalhar na escola, P1 lembrou que os PCNs orientam o trabalho com alguns gêneros da oralidade como debate, entrevista, exposição oral, entre outros. Diante da grande diversidade, comunga com os nortes do referido documento e ressalta a importância de se observar os gêneros em diferentes domínios discursivos e formas de articulação intertextual com demais gêneros (orais e escritos). P2 destacou os gêneros: apresentação oral, entrevistas, debates, narração, relato pessoal, exposição e descrição. É perceptível que os professores entendem que a diversidade de gêneros esteja presente no currículo de Língua Portuguesa, bem como, o trabalho conectado com gêneros das modalidades escrita e oral: noção essa coerente com a prerrogativa da linguagem como interação social. $\mathrm{O}$ debate, a entrevista e a exposição apresentam-se como gêneros privilegiados para ambos os docentes. Ressaltamos ainda que assim como os estudos teóricos pautados em pesquisas acadêmicas, os documentos oficiais, no campo da Educação, são importantes para direcionar as linhas de atuação em âmbito escolar.

Finalmente, no que concerne ao trabalho pedagógico do livro didático com a diversidade de gêneros orais, $\mathbf{P} \mathbf{1}$ alega que nem sempre os livros contemplam satisfatoriamente o trabalho com a oralidade. Por sua experiência de sala de aula, percebe que atualmente há um trabalho mais direcionado dos livros para o uso de gêneros da oralidade em se comparando com as publicações da década de 1990, por exemplo, mas ainda há muito que se avançar: a escrita é mais valorizada, os gêneros orais são menos explorados e quando o são, as propostas em muito são superficiais do ponto de vista do tratamento das características sociodiscursivas e textuais dos gêneros. P2 é enfático ao afirmar que os livros didáticos deixam a desejar quando o conteúdo é "gêneros da oralidade". Porém, também observa que nos últimos anos, a qualidade dos livros didáticos tem melhorado muito. Já sendo possível identificar uma variedade maior, porém, o trabalho demasiado 
com determinados gêneros em detrimento de outros ainda é perceptível, o que configura uma proposta pedagógica de baixa qualidade, cabendo ao professor de acordo com sua formação acadêmica, ampliar esse leque de oferta. Os docentes demonstram conhecer o histórico do livro didático quanto ao trabalho com a oralidade, bem como o papel das políticas públicas no sentido de melhoria da qualidade desse material pedagógico tão presente nas escolas públicas e privadas brasileiras. Em ambos os discursos, observa-se que há uma lacuna no que diz respeito às propostas de ensino-aprendizagem com os gêneros da oralidade.

Evidenciamos, com base na entrevista aos docentes de escolas públicas, que o ensino-aprendizagem de língua, centrado na diversidade dos gêneros textuais, oferece condições para que a aprendizagem seja mais significativa, tanto no que se refere ao trabalho com a oralidade quanto ao que tange ao trabalho com o letramento.

Além do estudo contextualizado dos gêneros, - considerando suas características sociais, discursivas e textuais - , mais especificamente quanto à oralidade, alguns tópicos de discussão não podem estar ausentes das aulas de Português: relações fala-escrita, relações "fala pública"-"fala privada”, níveis de formalidade, variedades linguísticas. Lembramos, todavia, que há uma inter-relação entre tais elementos.

Como já observamos, os gêneros textuais são diversos em suas realizações. Bakhtin (1997) destaca que cada esfera de organização social do discurso possui um leque de gêneros que permite aos sujeitos realizarem seus objetivos interacionais, por exemplo, no domínio da literatura, temos contos, poemas, cordéis, crônicas, romances; no do jornalismo, reportagens, entrevistas, notícias; no escolar, aulas, seminários, textos informativos; no esportivo, resenhas, regras de jogos, e tantos outros.

Os PCNs (1997) norteiam que o estudo da língua materna deve pautar-se na ideia de que o texto, com suas especificidades, trata-se de uma unidade de ensino basilar; e que ao estudá-lo é preciso observá-lo no seu contexto de produção-recepção como uma manifestação de um gênero. Nas orientações do referido documento, as práticas de ensino da língua devem possibilitar ao aluno aprender a linguagem a partir da diversidade de textos que circulam socialmente.

Os alunos, como cidadãos que participam de uma comunidade, se deparam com essa diversidade a todo o momento, seja em espaço público ou privado. O trabalho com as práticas de letramento e oralidade nos mais variados gêneros é relevante para que o repertório desses estudantes se amplie e, desse modo, para que eles possam compreender e produzir sentidos socialmente circulantes. 


\section{CONSIDERAÇÕES FINAIS}

Os aprofundamentos teóricos realizados nos nossos estudos nos mostram que um dos fatores de inclusão social é a participação significativa do indivíduo nas práticas sociais de uso da linguagem. Nesse caso, a escola, como espaço de sistematização do saber construído sócio-historicamente, numa perspectiva inclusiva, desveste-se de intolerâncias e preconceitos linguísticos, partindo para reflexão a respeito de como organizamos nosso discurso nas mais variadas situações, passando pelo respeito à diversidade das variedades linguísticas e pelo olhar crítico da cultura letrada. Assim, a oralidade e o letramento são objetos do trabalho pedagógico que visa à formação do aluno cidadão.

No que tange especificamente ao universo da fala, a nossa revisão bibliográfica aponta que o ensino e a aprendizagem da oralidade na sala de aula passam por ajustes para atender a linha sociointeracionista desenhada pelas pesquisas recentes, linha essa basilar para construção das competências linguísticas nas aulas de língua materna. Nesse campo, os gêneros textuais são enfatizados no currículo por serem primordiais como organizadores das nossas práticas sociais e discursivo-textuais. Os docentes entrevistados demonstraram estar cientes dessas proposições, revelando propriedade na sua formação acadêmica e uma preocupação com a qualidade dos seus trabalhos, uma vez que continuam em processo de formação acadêmica.

Ressaltamos que as competências atribuídas aos gêneros da oralidade perpassam por objetivos como: comunicarmo-nos adequadamente com o grupo; ouvirmos com atenção a fala do outro; expressarmos nossas ideias de forma complementar - com o auxílio da linguagem não verbal; interpretarmos e explicitarmos a compreensão sobre textos lidos; confrontarmos opiniões e pontos de vista diferentes do nosso; adequarmos a linguagem às comunicações formais do cotidiano escolar e social, dentre tantos outros.

Pelo exposto, reforçamos: as práticas de oralidade quando bem trabalhadas na escola, pensadas e implementadas com objetivo de ampliar as competências comunicativas dos alunos, possibilitando-lhes a inserção na sociedade, no exercício pleno da sua cidadania, representam, pois, a direção para a preservação de seus direitos, constituindo-se num importante recurso para levá-los a adquirir autoconfiança e construir sua autonomia, de sua afirmação como sujeitos partícipes do mundo letrado. 


\section{REFERÊNCIAS}

BAKHTIN, M. (Volochinov). Marxismo e filosofia da linguagem. 9. ed. São Paulo: Hucitec, 2002.

BAKHTIN, M. Estética da criação verbal. 2.ed. São Paulo: Martins Fontes, 1997.

BARDIN, Laurence. Análise de Conteúdo. Lisboa, Portugal; Edições 70, LDA, 2009.

BEZERRA, M. A. Ensino da língua portuguesa e contextos teórico-metodológicos. In.: Ângela Dionísio, Anna Rachel Machado e Maria Auxiliadora Bezerra (orgs.). Gêneros textuais e ensino. Rio de Janeiro: Lucerna, 2002.

BRASIL. SECRETARIA DE EDUCAÇÃO FUNDAMENTAL. Parâmetros curriculares nacionais: língua portuguesa. MEC, SEF, 1998.

MARCUSCHI, L. A. Oralidade e ensino de língua: uma questão pouco "falada”. In.: DIONÍSIO, A. P. \& BEZERRA, M. A. (orgs.). O livro didático de português: múltiplos olhares. Rio de Janeiro: Lucerna, 2001.

MARCUSCHI, L. A. Gêneros textuais: definição e funcionalidade. In.: Ângela Dionísio, Anna Rachel Machado e Maria Auxiliadora Bezerra (orgs.). Gêneros textuais e ensino. Rio de Janeiro: Lucerna, 2002. pp. 19-36.

MARCUSCHI, L. A. Da fala para escrita: atividades de retextualização. 5. ed. São Paulo: Cortez, 2004.

MINAYO, M. C. S. O desafio do conhecimento: pesquisa qualitativa em saúde. 10. ed. rev. e aprim. São Paulo: Hucitec, 2006.

SOUZA JUNIOR, Marcílio; MELO, Marcelo S. Tavares de; SANTIAGO, Maria Eliete. A análise de conteúdo como forma de tratamento dos dados numa pesquisa qualitativa em Educação Física escolar. Movimento, Porto Alegre, v.16, n.03, p.31-49, julho/ setembro de 2010.

Submetido em: 30/09/2019

Aceito em: 06/04/2020 